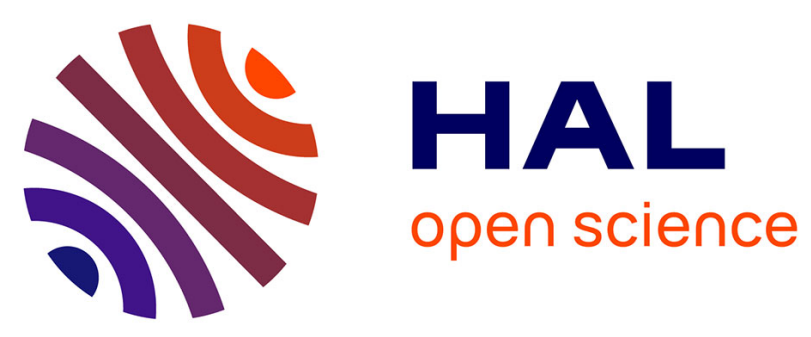

\title{
Neurophilosophy of Number
}

Hourya Benis Sinaceur

\section{To cite this version:}

Hourya Benis Sinaceur. Neurophilosophy of Number. International Studies in the Philosophy of Science, 2017, 31 (1), pp.1 - 25. 10.1080/02698595.2017.1370925 . hal-01659942

\section{HAL Id: hal-01659942 https://hal.science/hal-01659942}

Submitted on 9 Dec 2017

HAL is a multi-disciplinary open access archive for the deposit and dissemination of scientific research documents, whether they are published or not. The documents may come from teaching and research institutions in France or abroad, or from public or private research centers.
L'archive ouverte pluridisciplinaire HAL, est destinée au dépôt et à la diffusion de documents scientifiques de niveau recherche, publiés ou non, émanant des établissements d'enseignement et de recherche français ou étrangers, des laboratoires publics ou privés. 


\section{International Studies in the Philosophy of Science}

\section{Neurophilosophy of Number}

\section{Hourya Benis Sinaceur}

To cite this article: Hourya Benis Sinaceur (2017) Neurophilosophy of Number, International Studies in the Philosophy of Science, 31:1, 1-25, DOI: 10.1080/02698595.2017.1370925

To link to this article: http://dx.doi.org/10.1080/02698595.2017.1370925

\section{Published online: 14 Nov 2017.}

Submit your article to this journal $\llbracket$

Q View related articles $₫$

View Crossmark data $\nearrow$ 


\title{
Neurophilosophy of Number
}

\author{
Hourya Benis Sinaceur \\ Institut d'Histoire et de Philosophie des Sciences et des Techniques
}

\begin{abstract}
Neurosciences and cognitive sciences provide us with myriad empirical findings that shed light on hypothesised primitive numerical processes in the brain and in the mind. Yet, the hypotheses on which the experiments are based, and hence the results, depend strongly on sophisticated abstract models used to describe and explain neural data or cognitive representations that supposedly are the empirical roots of primary arithmetical activity. I will question the foundational role of such models. I will even cast doubt upon the search for a general and unified philosophical foundation of an empirical science. First, it seems to me hard to draw a global and coherent view from the innumerable and piecemeal neuropsychological experiments and their variable, and sometimes uneasily compatible or fully divergent interpretations. Secondly, I think that the aim of empirical research is to describe dynamical processes, establishing correlations between different sets of data, without meaning to fix an origin or to point to a cause, let alone to a ground. From the very scientific and philosophical point of view it is essential to distinguish between explanations, which provide correlations or, at best, causal mechanisms, and grounding, which involves a claim to some form of determinism.
\end{abstract}

\section{Introduction}

Gottlob Frege's question in the first sentence of the introduction to The Foundations of Arithmetic is: 'What the number one is, or what the symbol 1 means?' (Frege [1884] 1953, xiii).

Frege's answer to this question is that numbers are objects and assert something about a concept. In the process of getting this answer, Frege does not allow himself to draw on sensations, mental pictures or acts, consciousness, historical development, natural selection, etc. Let me recall some of Frege's prerequisites:

No, sensations are absolutely no concern of arithmetic. No more are mental pictures ... All these phases of consciousness are characteristically fluctuating and indefinite, in strong contrast to the definiteness and fixity of the concepts and objects of mathematics.

Psychology should not imagine that it can contribute anything whatever to the foundation of arithmetic.

CONTACT Hourya Benis Sinaceur houryabenis@yahoo.fr $\Theta$ Institut d'Histoire et de Philosophie des Sciences et des Techniques, UMR 8590, 13, rue du Four, 75006 Paris, France 
Never let us take a description of the origin of an idea [Vorstellung] for a definition, or an account of the mental and physical conditions on which we become conscious of a proposition for a proof of it.... [We] reckon twice two as four regardless of the fact that our idea of number is a product of evolution and has a history behind it.

[Defining numbers psychologically] in terms of the nature of human mind, ... makes everything subjective, ... and does away with truth. (Frege [1884] 1953, xvii, xviii, xviii, xix)

Today, the first question is 'how?' and the tools used for answering it give the key for answering the what-question. Indeed, from the point of view of neurosciences and cognitive ${ }^{1}$ sciences the question is: 'How do we extract numbers from our perceiving the surrounding world?'. And the goals and means of the investigation are totally opposed to Frege's views, since the answers to the question are based on the process of natural selection, the neurobiological architecture of the brain and the psychological operations of the mind. Therefore the nature of numbers is understood in a way that straightforwardly conflicts with Frege's conception.

Actually, the philosophical perspective of cognitive sciences is definitely empiricist. But, at the same time, most cognitive scientists believe in the existence of universal structures of cognition engraved in the functional architecture of the brain. Contrary to Jean Piaget's constructivism, according to which people gradually construct knowledge and form meaning based upon their experiences and experiential learning, most cognitive scientists endorse the hypothesis of quasi-innate mechanisms of perception and conception; therefore, they advocate a strongly rationalistic nativism. ${ }^{2}$ The Darwinian empiricism of neuroand cognitive sciences is a naturalised rationalism.

Noam Chomsky, the analytic philosopher and father of modern linguistics, was one of the founders of cognitive sciences. His idea of the universal grammar as a mostly innate body of knowledge possessed by language users played a big role in the decline of the associationist view of behaviourism, also of Locke's and Skinner's view of the mind as a tabula rasa and of language as learned skill, and of Piaget's constructivism. Chomsky promoted nativism, according to which specific skills and abilities are innate and hard-wired into the brain at birth.

As a philosopher of mathematics, I am fascinated by the discoveries of neurosciences and cognitive sciences about numbers and calculation. I have gathered much material on the subject and I will try to present a synthetic view of the results and ideas I got from it. I do not want to give a large space to a detailed description of the so many experiments that have been performed. My aim is to focus on the conceptual and philosophical background of those experiments and I will rather ask some questions about the underlying views, which seem to me open to discussion. In particular I will bring to light the petitio principii, which is most times involved in neuropsychological arguments. Moreover I will cast doubt on the primary aim to give foundations to our most elementary concepts and operations of arithmetic. (For a more detailed study see Benis Sinaceur 2014b, 2016. Yet my philosophical views are more elaborate in the present article.)

\section{Experiments}

Neurosciences and cognitive sciences provide us with myriad empirical findings that shed light on hypothesised primitive numerical processes in the brain and in the mind. Actually, neurophysiological and cognitive experiments have remodelled our knowledge of the 
cerebral and psychological components of our ability to estimate, compare and calculate quantities and solve elementary arithmetical problems.

Roughly there are three main types of empirical tests.

(1) Functional neuroimaging, especially functional magnetic resonance imaging (fMRI), allows visualising which regions of the brain are activated when a subject performs certain arithmetical tasks. Maps of neural circuits in activation can be correlated with specific arithmetical activities. However, fMRI allows relatively poor temporal resolution: it may not pick up transient pattern of brain activity.

(2) Electroencephalograhy (EEG) scans measure electric activity in the brain through electrodes on the scalp; they can pick up quick changes in brain activity but have poor spatial resolution, as only areas at the surface of the brain can be accurately measured.

(3) Experimental psychology aims at detecting the mental operations or representations of animals, infants or adults through their observable behaviour when they are asked to perform some arithmetical task. Inferences are made from what is actually observed to what is putatively executed by the mind or represented in the mind. Cognitive sciences reject also the idea that only public events (behaviours of individuals) can be objectively studied and that therefore private events, such as emotions, feelings and thoughts, should be ignored.

Those three main methodologies are combined with many others, such as the 'violation-of-expectation looking-time methodology', ethnological data, tests on braindamaged patients, methods of computer science, artificial intelligence, linguistics, anthropology, philosophy, etc. The goal is to give accounts of the operations of the mind. Two main global approaches are endorsed. On the one hand, computational scientists (Hilary Putnam, Jerry Fodor, Zenon Pylyshyn) assume the hypothesis that the mind operates by performing purely formal operations on symbols, like a computing machine. They assimilate the brain to an information-processing system with representational structures so that the mind is the result of the programme that the brain runs. Thinking is a form of computing. In Fodor's original views, the computational theory of mind is also related to the 'language of thought' (the mentalese), which allows the mind to process more complex representations with the help of semantics (Fodor 1975). Pylyshyn also assumes the mentalese hypothesis (Fodor and Pylyshyn 1988).

On the other hand, connectionists (such as Jeffrey Elman) incorporate dynamical systems theory and model mental phenomena as emergent processes of neural interconnected networks. They replace theoretical appeals to syntactic rules of inference and sentence-like cognitive representations with appeals to the parallel processing of diffuse patterns of neural activity. They believe that brain processing is non-symbolic and they invoke neither the ontological category of representations nor the language of thought. As a version of this approach there is Lawrence W. Barsalou's theory of perceptual symbol systems (Barsalou 1999), which bases symbolic functionality on simulation and dynamic systems. Connectionism and computationalism need not be at odds: many researchers argue that they are fully compatible and some think that the connectionist architecture embodies the way in which organic brains implement the symbol manipulation system. Actually, both models assume the immanence of arithmetical calculus in nervous activity and mental functions: studies show that individual neurons utilise a 
wealth of nonlinear mechanisms to transform synaptic input into output firing, and that these mechanisms enable the neurons and the neuronal networks to perform a range of arithmetic operations on signals encoded in a variety of different ways (Dehaene and Cohen 1997; Nieder 2005; Silver 2010; Dehaene 2011, 247-254). As a consequence of the immanence assumption, neuroscientists develop a harsh criticism against behaviourism and constructivism.

Indeed, the cognitive trend rules out the basic premise of behaviourism, which is that the study of behaviour should be a natural science, such as chemistry or physics, without any reference to hypothetical inner states of organisms. On the contrary, most cognitive researchers assume as fundamental hypothesis the sui generis reality of the mental, and combine the naturalistic testing of the behaviour with the (indirect) study of the representational structures of the mind, that is to say the study of how information is represented and transformed in the mind in faculties such as perception, memory, attention, emotion, language and reasoning. The emphasis on information processing entails that the hallmark of psychological theory is no longer observable behaviour, but rather the recording and modelling of mental states. Marcus Giaquinto rightly points out that cognitive scientists defend a form of mentalism. He objects that

The big problem for any version of mentalism is that only finitely many brain states have actually been realised; hence, there are only finitely many mental entities, whether innately given or produced by intellectual activity or a combination of the two. (Giaquinto 2015, 20)

A way out might be that although the brain and the mind do not store the infinity of numbers, they have available small numbers and the process generating any number.

The cognitive trend dissents also from Piaget's constructivism. Piaget denied young children innate numerical abilities. He identified assimilation and accommodation as mechanisms by which information from the environment and ideas from the individual interact and result in internalised structures developed by learners. According to Piaget [1953] 1973), the number concept is progressively constructed through a logico-mathematical synthesis of operations such as classification, ordering, recollection of discrete quantities. Piaget distinguishes four stages of cognitive development:

- Sensorimotor stage (babies who are 0-2 years old);

- Preoperative stage (2-6 years);

- Operative stage (6-10 years): ability for concrete arithmetical operations;

- Abstract stage (10-16 years): ability for abstract calculating.

But new methods of experimenting, which were not available to Piaget, show that very young babies recognise that something has changed in a small collection when an object has been removed or added (see e.g. the section, 'Piaget's Errors', in Dehaene 2011, 33$36){ }^{3}$ One of the basic methods consists in considering looking times as a source of data concerning infants' perception and representation of events and objects that unfold before them. Infants look longer at new, non-expected, improbable or impossible events than at ordinary ones. ${ }^{4}$ Elizabeth S. Spelke states that, contrary to Piaget's belief, infants know right from birth some fragments of arithmetic comparable to the animal knowledge of number. Elementary additions and subtractions are available very early (Wynn 1992). Babies have also what she called an arithmetical 'core cognition'. Spelke writes: 
Adults have a core conception of objects, and it is the very conception with which infants are born. Development brings us new conceptions, some of them quite general, but these new conceptions do not displace the core cognition. New conceptions of objects grow on the periphery of a set of notions that are innate, that are present throughout life, and that do not change. (Spelke 1983, 29; cf. Carey 2009, 40)

Moreover babies' knowledge acquisition is much more flexible than supposed by Piaget. Scientists have given evidence of neural plasticity and of neural reuse as fundamental organisational principles of the brain: neural circuits established for one purpose can be exploited, recycled, redeployed during evolution or normal development, and can be put to different uses, often without losing their original functions (Anderson 2010; Anderson and Penner-Wilger 2013).

\section{Theoretical Project}

What is the theoretical aim of all those biological, neurophysiological and psychological studies?

To answer this question I will reproduce the claims made by two leading scientists, Stanislas Dehaene and Susan Carey, who represent major trends in the vast field of brain and mind research:

I hope that empirical findings might shed light on ancient philosophical disputes that question the very nature of mathematics. (Dehaene 2011, ix-x)

My goal here is to demonstrate that the disciplines of cognitive science now have the empiri$\mathrm{cal}$ and theoretical tools to turn age-old philosophical dilemmas into relatively straightforward scientific problems. (Carey 2009, 4)

Carey's and Dehaene's aim seems to be similar, mutatis mutandis, to Hilbert's programme to solve philosophical and epistemological questions about the foundations or the nature of mathematics by mathematical tools (Hilbert 1918). Indeed, Carey's and Dehaene's basic goal is to answer philosophical and epistemological questions through empirical testing and mathematical techniques for recording and analysing data produced by testing. Actually, mathematics seems to be viewed by neuroscientists and cognitive researchers not only as an investigation and analysis tool, but also as a very right expression of biological and psychological data. But conversely biology and psychology are supposed to give empirical grounding for thinking and calculating. Searching for neural/cognitive foundations for mathematical, and more generally for conceptual capacities, is the theoretical project supporting all kinds of experiments.

I will briefly report on Dehaene's and Carey's enterprises, as they differ on some important points. My aim is to examine the conceptual and philosophical assumptions underlying the general picture or theory they provide for describing the presumed neural or cognitive, material or symbolic, actual foundations for our elementary arithmetical abilities.

\section{Stanislas Dehaene's Analysis}

\subsection{Dehaene's 'Number Sense'}

On the one hand, Dehaene maintains that there are biological bases that really explain or materially cause early arithmetical capacity. He thinks that the structure of the brain is 'the 
single source' of elementary arithmetical knowledge (Dehaene 2011, xvii). According to him, numbers are engraved in the architecture of our brains as an outcome of a slower evolution governed by the principles of natural selection. On the other hand, Dehaene thinks that arithmetic reasoning captures objective properties of the world, which the brain, animal or human, must represent in order to act effectively in it. Interaction between brain and environment produces what I call a 'post-established' and scalable harmony, since it is a result of evolution and selection (Darwinism).

Thus, the organism's adaptive reactions to the environment have presumably shaped a sixth sense, the 'number sense', which provides animals and humans with a sensory perception of the 'numerosity' of the objects in a group or a collection. The idea of and the term 'number sense' originated from Tobias Dantzig's book, Number: The Language of Science (Dantzig 1954), and they became very popular through Dehaene's work.

Numerosity is not yet number. It is the approximate quantity of the items in a group of things. According to Dehaene, the number sense gives humans the intuition of number through the native competence for processing approximate quantities. For instance, babies and animals are not able to distinguish 48 from 50 objects; only words and symbols can separate arbitrary close quantities. But apprehending the numerosity is independent of language and symbols. It is a dimension of direct sensory perception: babies and animals perceive the difference between not too big and not too close quantities, for instance between 8 things and 16 things or between 16 and 40 (Wynn 1998; Butterworth 1999; Xu and Spelke 2000). Dehaene thinks that computing the numerosity of objects in a set 'is probably no more difficult than perceiving their colours or their positions' (Dehaene $2011,12)$. In short, numerosity is a natural and primitive datum, whereas the number is a cultural concept.

It is generally admitted that the intraparietal sulcus of the brain houses the circuitry that is fundamentally involved in estimation and comparison of numerosities (Simon et al. 2002; Nieder and Miller 2003, 2004; Roitman, Brannon, and Platt 2007, 2012; Dehaene 2011, chapters 7 and 8). The inferior parietal lobe, the frontal lobe and regions involved in language processing are active in calculation tasks. Dehaene and his colleagues suggest that these two parietal structures play complementary roles and they argue for a down-top continuity between the primary unconscious intuition of numerosities and the progressive verbal and symbolic construction of numbers.

I will set out briefly the main characteristics of the 'number sense'.

(1) The number sense is a fuzzy vision, which extracts numerosity of collections of objects in a direct, immediate, non-linguistic and non-symbolic way: that is the 'subitizing' ability. Thanks to perceptual vision of events and objects of the world, we intuitively understand what cardinal numbers mean, that is to say we grasp without any calculation how big is the numerical size of objects and events: animals and babies discriminate between two different quantities (between one dot and two dots on a screen) and they choose spontaneously the larger of two numerical quantities of crackers or candies.

Having a specific intuition of numerosities does not imply that numerosity is independent of the architecture of the brain or of the basic structures of cognition. Intuition means the learned agreement between the brain and the world, thanks to which we get an immediate and approximate understanding of magnitudes. 'Some mathematical 
objects now seem very intuitive only because their structure is well adapted to our brain architecture' (Dehaene 2011, xxi; this means clearly a post-established harmony).

(2) The number sense handles continuous estimates and it judges magnitudes approximately. Animals, chimpanzees for instance, and babies do not possess a discrete representation of numbers. Animals have a 'fundamental inability to represent numbers 4, 5 and 6 in a discrete and individualized format' (Dehaene 2011, 19, 45); they have only an approximate and continuous representation of numbers. Newborns have a discrete representation only of small numerosities; they can actually readily distinguish one object from three, but rarely two from three, and never two objects from four objects, four from six or eight from twelve (Xu and Spelke 2000). By contrast, 'with the approximation system, we have an immediate intuition about the continuity of numbers' (Dehaene 2011, 258). Number is also represented as continuous mental magnitudes by nonhuman animals, human infants and adult humans.

(3) The number sense grasps the cardinal aspect long before the natural ordering of numbers. Before the age of about 15 months 'babies can recognize one, two, or three objects and even know that 1 plus 1 makes 2, without necessarily realizing that three is larger than two, or that two is larger than one' (Brannon 2002; Dehaene 2011, 51) - this assumption is not generally shared, in particular not by Carey and her colleagues. ${ }^{5}$

(4) The number sense grasps an abstract property of objects or events in the world, namely their size of magnitude, in a quasi-sensory way.

(5) The number sense needs the help of words and symbols to go beyond estimation and approximation, and to handle discrete quantities and exact number calculations (Dehaene and Cohen 1991). The number sense is neither the ability to count nor to do proper calculations, but the ability to recognise quantitative changes in a phenomenon, an event, or a collection.

In a nutshell, we perceive numerosities and we create (symbolic) numbers: 'The number sense that we inherit from our evolutionary history plays the role of a germ favoring the emergence of more advanced mathematical abilities' (Dehaene 2011, 29).

Note that the term 'abstract' is paradoxically used in the case of the intuitive grasping of the approximate cardinality of a collection of events or objects as well as in the case of symbolic exact calculation. Actually Dehaene uses 'abstract' with a variable meaning. For the sake of clarification let me distinguish at least four meanings.

First, 'abstract' means 'amodal': the representation of numerosity is not specifically tied with vision, audition, or touch (Church and Meck 1984; Dehaene 2011, 39-41, 50). ${ }^{6}$ Many experiments show that infants can match through one-to-one correspondence the number of sounds they hear with the number of dots they simultaneously watch (Spelke 1983; Starkey, Spelke, and Gelman 1983, 1990; Wynn 1996; Feigenson and Spelke 1998; Lécuyer 2002; Izard et al. 2009; Dehaene 2011, 39-41). The same representation of number 'three' seems to fire in babies' brain, whether they see three dots or hear three sounds.

Secondly, 'abstract' means 'independent' of the form of presentation (puppets, dots, small cars or Arabic numerals) and from size, shape and colour. Four-and-a-half-month-old infants are not surprised by changes in object appearance in the course of arithmetical operations. If two puppets are first presented, infants are not surprised if the puppets are replaced by two balls; they are also not much disturbed by changes in object identity. Yet their attention 
is aroused when only one puppet is to be seen, that is, when numerical identity changes (Izard, Dehaene-Lambertz, and Dehaene 2008; Dehaene 2011, 44). But how to be sure that such changes are really perceived as quantitative changes and not only as changes in the global shape of the totality of objects showed? There is no unique and uniform answer to this question. On the base of some tests, Dehaene thinks that babies are capable of noticing the change of number regardless of the variability of other parameters in the display of two versus three items, small or large, aligned or not, black or red, etc. (Dehaene 2011, 38-39).

Thirdly, subitising the size of a group of objects is grasping the numerical aspect of the group regardless of the material size, material identity, shape, colour, etc. of the individual objects and regardless of the material quantity present in the totality of objects. Chimpanzees and infants choose the biggest total number of small chunks of chocolate rather than the smaller number of larger chunks (Feigenson, Carey, and Hauser 2002). ${ }^{7}$ Therefore one might think that they really perceive numerical identity as a specific abstract property (Lourenco and Longo 2010).

Fourthly, 'abstract' refers to a symbolic representation, such as I, II, III, etc. or 1, 2, 3, etc. With such symbols we leave the domain of intuitive and approximate, possibly verbal, estimation of quantity for a symbolic and discrete representation of numbers, coding exact quantities (Izard, Pica, et al. 2008. On mathematical abstraction see Benis Sinaceur 2014a).

According to Dehaene, subitisation corresponds to the activity of the Analogical (or Approximation) Number System (ANS), which exists in the animal and human brain. Dehaene writes indeed:

Subitizing in human adults, like numerosity discrimination in babies and animals, depends on circuits of our visual system that are dedicated to localizing and tracking objects in space. The occipitoparietal areas of the brain contain neuronal ensembles that rapidly extract, in parallel across the visual field, the location of surrounding objects. (Dehaene 2011, 57)

According to Dehaene (and many others) there is an essential link between quantitative and spatial representations, which is rooted in the brain's organisation (Carey and Xu 2001; Walsh 2003; Hubbard et al. 2005; De Hevia and Spelke 2010; Chinello et al. 2013; Spelke et al. 2014). Let me quote only one passage:

Many behavioural and patient studies have shown that numerical-spatial interactions run far deeper than simply cultural constructions, and, instead, influence behaviour at several levels. By combining two previously independent lines of research, neuroimaging studies of numerical cognition in humans, and physiological studies of spatial cognition in monkeys, we propose that these numerical-spatial interactions arise from common parietal circuits for attention to external space and internal representations of numbers. (Hubbard et al. 2005, 435)

The spatial-numerical association of response codes (SNARC) implies that the core semantic representation of numerical quantity can be linked with a mental number line (MNL), a quasi-spatial representation in the brain on which numbers are organised by their proximity (Dehaene, Bossini, and Giraux 1993; Gallistel and Gelman 2000, 2005; Dehaene 2001, 3). ${ }^{8}$ The supposed MNL is continuous, analogical and oriented left-to-right just like the direction of writing - at least in Western languages; it is localised bilaterally in the intraparietal sulcus of the human brain and is ordered logarithmically (Dehaene and Changeux 1993; Dehaene 2011, 64-66). ${ }^{9}$ Subitising is submitted to a distance effect and to a magnitude effect: we more easily distinguish distant numerosities, such as 80 and 100, than closer 
ones, such as 80 and 81 ; for an equal distance we discriminate less easily two large numerosities, such as 80 and 100, than two small ones, such as 8 and 16 .

It seems that we have inherited a core analogical representation of quantity, 'analogical' as opposed to 'digital' (Platt and Johnson 1971; Carey 2009, 118-137; Dehaene 2011, 6164, 218-220). According to Dehaene, even the availability of precise number symbols does not obliterate the continuous representation of quantities. Summarising his point of view, Dehaene writes:

My hypothesis is that the number sense qualifies as a biologically determined category of knowledge. I propose that the foundations of arithmetic lie in our ability to mentally represent and manipulate numerosities on a mental 'number line', an analogical representation of number; and that this representation has a long evolutionary history and a specific cerebral substrate. Numbers appear one of the fundamental dimensions according to which our nervous system parses the external world. Just as we cannot avoid seeing objects in color (an attribute entirely made up by circuits in our occipital cortex) and at definite locations in space (a representation reconstructed by occipito-parietal neuronal projection pathways), in the same way numerical quantities are imposed on us effortlessly through the specialized circuits of our parietal lobe. The structure of our brain defines the categories according to which we apprehend the world through mathematics. (Dehaene 2011, 245; emphasis added)

\subsection{Criticism of Dehaene's Point of View}

(a) Rafael Núñez argues that the number line, although ubiquitous in the modern world, is not universally spontaneous, but rather seems to be learned through-and continually reinforced by-specific cultural practices. Let me quote Núñez verbatim:

The number line as well as the mental representation that it entails emerges outside of natural selection proper requiring the mediation of high-order non-numerical cognitive mechanisms such as fictive motion, conceptual mappings (e.g. conceptual metaphor), and external representational media. (Núñez 2011, 652)

If, as experts say, Babylonians conceptualized number essentially as an adjectival property of a collection or of a measured object [i.e. not as itself an object], we cannot conclude on the basis of YBC 7289 that Old Babylonians operated with a fundamental number-to-line mapping. (Núñez 2011, 655; emphasis added)

Indeed, we learn from the history of mathematics that there was no number line in old Babylonian tablets, no mapping between real numbers and a real geometric line in René Descartes's La Géométrie (1637), the book in which geometrical problems were systematically resolved through solving algebraic equations. Actually, it was John Wallis who introduced, for the first time, the concept of number line in his Treatise of Algebra (1685).

(b) Dehaene assumes a kind of homology between the physical world and the form and content of our perception of the world. In particular the MNL is apparently based on the same system used to represent physical space. Actually, Dehaene bases on the continuity of many physical phenomena, including the flow of sensory information and the transmission of nerve impulses, the priority of:

- A continuous, fuzzy and global perception of numerosities over a discrete and segmented apprehension of isolated unities; 
- The cardinal aspect of number over its ordinal and serial aspect;

- The geometrical continuum over the algebraic definition of real numbers.

Using a geometrical model of the continuum for describing neural facts and putative primary cognitive acts or mechanisms might be a heuristic device. But taking this model as yielding a universal genetic foundation poses a double problem. First, the clear and explicit notion of mathematical continuity is relatively recent (not before the seventeenth century and differential calculus), and the concept of numerical continuity even newer (nineteenth century with Georg Cantor, Richard Dedekind, Charles Méray, Karl Weierstrass). Secondly, how to think the link between a certainly fruitful model $M$ and the bare reality, if ever we could have access to the 'bare reality'? The answer is not simple, but clearly one has to keep a critical distance between the model $M$ and the reality whose some-probably not all-aspects are simulated by $M$.

There are three more questions to which no definite answer seems to be available.

- To which extent can a highly sophisticated numerical model open the route to the origin of the human numerical ability? (Of course, I do not question the fruitfulness and legitimacy of such a model in case of analysing our current ability.)

- Why should we analyse interactions between the brain/mind and the environment in terms of origin and deterministic causality? Why not just in terms of dynamical/dialectical interactions between the two poles without fixing the origin or cause in one of them? ${ }^{10}$

- Does a model provide a foundation? Or does it just improve our understanding and suggest new means for educational programmes?

The responses are varied, nuanced, and not immune to global, tacit or explicit, philosophical views. Anyway, one should keep in mind that correlation between neural circuits and arithmetical understanding or doing is correlation; it does not necessarily mean that the neural activity is the very first origin or cause for perceiving or understanding the numerical aspect of things and events. Neural maps do not, per se, justify the materialist and deterministic reductionism of Dehaene and Changeux (1993). I must point out in passing that, in defending an opinion that is diametrically opposed to Frege's point of view, neuroscientists share with Frege the aspiration for a foundation, just replacing definition and proof by origin and cause. The paradoxical alliance of empiricism with foundationalism warrants at least a critical examination, if not a justification.

Last but not least: the use of words and concepts, such as 'meaning', 'intuition', 'format', 'content', 'abstract', 'concrete', etc., is rather fuzzy in Dehaene's writings. The distinction made between 'numerosity' and 'number' is pretty often blurred. Even the sense of the adjective 'continuous', which plays a so central role in the views displayed, is not carefully fixed. Should one understand by 'continuous' and 'continuity' the common coarse concepts or more theoretical concepts? And if it is question of mathematical concepts, should one not distinguish between geometrical and numerical continuity? Moreover, since it is taken as primitive and immediate, the idea of 'numerical identity' is used without being subjected to a conceptually more meticulous inquiry. After all, what counts as the numerical identity of a plurality of objects? If we have to discriminate numerosity and number, grasping quickly the numerosity of a plurality does not lead 
directly (not without mediating conceptualisation) to a sharp notion of numerical identity: it is why it is hard to discriminate at a glance between 80 and 81 . Therefore it is not fully consistent to say that in grasping the numerosity of some plurality we grasp intuitively its numerical identity: numerosity denotes a non-accurate quantitative size, not numerical identity proper. In a word, quantity is not number.

\section{Susan Carey's Analysis}

Carey aims at giving the cognitive, rather than the neural, foundations of concepts including numerical concepts and she argues for an alternative model to the ANS model. The specific difficulty in cognitive experiment is that what the observed persons or animals do is not a perfect indicator of what they know or understand.

Let me first summarise Carey's global view in a few words.

(1) Carey defends a kind of psychological essentialism, assuming Susan Gelman's view (Gelman and Wellman 1991; Gelman 2003, 2004; Carey 2009, 22), according to which children and adults construe classes of entities, particularly biological categories, in essentialist terms, that is, as if category members had an immutable underlying essence, which gives them their identity and can be used to predict unobserved similarities between them. Experiments show that essentialism is an early cognitive bias: children have an early tendency to search for hidden permanent features beyond the obvious. Yet, essentialism is philosophically highly questionable, and it is even criticised from within by some cognitive scientists as being a move away from Darwinism (Palmer and Donahoe 1992; Palmer 2002).

(2) Carey defends also a version of what is labelled the 'theory-theory' of concepts (Gopnik 2003). She thinks indeed that children naturally attempt to construct theories to explain their observations, and learn through a process of theory revision closely resembling the way scientists propose and revise theories: they get less and less naïve theories by making a series of personal conceptual revolutions. In particular, Carey assumes Spelke's view that infants have a naïve physical theory of the objects and events they watch. ${ }^{11}$ However, she distinguishes between naive theories and core cognition, pointing out that 'the output of the core cognition systems is part of the input to theory building' (Carey 2009, 24).

\subsection{Concept and Content}

Carey rightly makes fundamental distinctions between object and concept, and between format and content. Let me quickly describe how she understands 'concept' and 'content' and their relations to objects (Carey 2009, 3-25). I will turn below to her distinction between content and format.

(1) Concepts are mental representations, 'just a subset of the entire stock of a person's mental representations, which naturally includes sensory representations and perceptual representations'. 
(2) Representations are states of the nervous system having content, that is, referring to concrete, abstract, or fictional entities, or to events, or to properties.

(3) The content of a concept is what it contributes to the meaning of a proposition in which it figures: content and meaning are taken as synonymous.

(4) Conceptual content is determined by:

a. causal mechanisms connecting a mental representation to the world; there is a causal link between a real world object or event and the mental representation of this object or event, and

b. computational processes in the mind that determine how the representation functions in thought.

(5) There are two kinds of conceptual representations: those embedded in systems of core cognition and those embedded in explicit knowledge systems. Carey's conception is based on Ned Block's vision of a dual factor theory of the determinants of conceptual theory (Carey 2009, 514-523).

(6) Young infants' representations of objects are conceptual in the double sense that their content cannot be stated in terms of sense data, and that they play an inferential role.

(7) The new representational resources emerge in development, which involves important discontinuities, which are conceptual changes.

(8) The bootstrapping strategy underlies the construction of new representational resources that are more complex and more powerful than their input and this without external supply.

\subsection{Core Cognition: Two Systems}

Contrary to the opinion that there is only one non-verbal system for representing number (Gallistel and Gelman 1978), Carey distinguishes two systems of core cognition with numerical content (Feigenson, Carey, and Spelke 2002; Xu 2003; Feigenson 2005; Hyde and Spelke 2009, 2011): ${ }^{12}$

Core system 1: analogical representation of number, which is grosso modo Dehaene's 'number sense'. According to Carey, this system functions only, or preferentially, for large sets of items. However, some experiments (Starr, Libertus, and Brannon 2013; Coubart et al. 2014) seem to support the idea that the ANS can represent any number, large or small.

Core system 2: parallel individuation and object tracking, which is preferred for representation of small sets (Feigenson and Carey 2003; Carey 2009, chs. 3-4). ${ }^{13}$

Already in the two systems of core cognition object representations are conceptual and are created by innate perceptual input analysers, and the two operate throughout the life span.

The distinction between content and format ${ }^{14}$ plays here a crucial role, permitting to reconcile the continuum of physical phenomena with the discrete character of perception and thought. According to Carey, the format of the parallel individuation is iconic, then analogical, but the content is discrete. Actually, when a small group of objects (one, two, three, or at most four objects) is presented, we extract representations of discrete individuals from the continuous sensorial input:

Sensory input is continuous. The array of light on the retina is not segregated into individual objects. Yet distinct individuals are provided by visual cognition as input into many other perceptual and cognitive processes. It is individuals we categorize into kinds; it is individuals we 
reach for; it is individuals we enumerate; it is individuals among which we represent spatial relations such as 'behind' and 'inside'; and it is individuals that enter into our representations of causal interactions and events. (Carey 2009, 70; cf. Carey and Xu 2001, 179-180)

In short, we spontaneously digitalise continuous phenomena into discrete entities.

\subsection{Parallel Individuation and Object Tracking}

Parallel individuation consists in creating in the non-verbal working memory an image of the object presented. This image is called 'visual index' or 'object-file'. Pylyshyn's visual index is treated as an element of the physiological structure of vision, whereas Carey's object-file is a mental image. By contrast with visual indexes in which only attention plays a role, ${ }^{15}$ object-files and objet tracking take into account time and space parameters and the role of working memory.

Carey's object-file is a mental representation; it may be an image-like representation (a picture, which need not be a duplication), for instance the image of an apple for a real apple, or it may be a symbol, for instance $\square \square$ or •• for two apples. When you add one apple more, the representation becomes $\square \square \square$ or $\bullet$.•, etc. Thus for each world-object a mental file is opened and tagged. There is a size limit on the number of objects that may be simultaneously attended to and represented in working memory: the number of files that can be simultaneously tracked is limited to three or four.

The object-file has an iconic, analogical, format: it does not involve sentence-like symbol structures, whereas the content is constituted by a very small number of discrete elements. Parallel individuation is associated with a mechanism of tracing numerical identity over time and space: infants use evidence of spatio-temporal discontinuity as a basis for individuating objects, and they distinguish one object seen on different presentations from two numerically distinct objects: young (10-month-old) infants prefer spatio-temporal information over property/kind information, which appears later at about the age of 12 months (Xu, Carey, and Welch 1999). ${ }^{16}$

Contrary to Piaget, Carey maintains that a child need not have achieved full sensorimotor development to create representations of enduring objects without having direct perceptual access to them ('out of sight' is not 'out of mind'). The spatio-temporal continuity involved in object permanence is the output of an innate capacity. And contrary to Quine, Carey thinks that psychological tests show that infants need not to construct explicit quantificational devices of language in order to create representations that distinguish between the same one and a different one. Further, Carey argues that representation of object cannot be reduced to sensorimotor or perceptual primitives, that core cognition has rich integrated conceptual content, and that representations from distinct core cognition systems interact in central inferential processes (Carey 2009, ch. 3):

I agree with [Renée Baillargeon, Randy Gallistel, Rochel Gelman, Alan Leslie, and Elisabeth Spelke] that the cognition of humans, like that of animals, begins with highly structured innate mechanisms designed to build representations with specific content. (Carey 2009, 67)

Being the output of innate input analysers and having iconic format, object-files are perceptual representations, but they are also conceptual representations non reducible to perceptual primitives. Before trying a critical analysis of the notion of object-files I will first summarise the depiction of it available in Carey's work. 


\subsection{Six Characteristics of the Representation via Object-files}

Representation via object-files has the following characteristics:

(1) The representation via object-files, although limited to small groups, is precise.

(2) Object-files are based on principles of individuation and numerical identity: only entities with clearly articulated properties of physical bodies can be represented-'physical bodies' means bounded, separable, three-dimensional, moving in a continuous spatio-temporal path bodies.

(3) Objects are represented as solid entities in spatio-temporal and causal relations to each other (physicalism). Let me quote:

Most general is the sortal bounded physical object itself, for which spatio-temporal properties provide the criteria for individuation and identity. More specific sortals, such as dog or car, rely on additional types of properties to provide criteria for individuation and identity. We conjecture that young infants might represent only the general sortal, object and construct more specific sortals later (the Object-first Hypothesis). This is closely related to Bower's 1974 conjecture that infants use spatio-temporal information to trace identity before they use property information. (Xu and Carey 1996, 111; emphasis in original)

(4) A file may be empty, and it may code an object without necessarily ascribing features to it or describing its properties: an object is not a bundle of features (essentialism).

(5) Opening a new file provides a mechanism for adding an item to an array of items, an operation which might be the 'wild' precursor of the successor function, the latter being understood later on: unlike Dehaene, Carey seems to give priority to the ordinal aspect of numbers over their cardinal aspect.

(6) Object-files involve the one-to-one correspondence: one file for each object. They might be also the primary root of apprehending, in small sets, the equinumerosity of different groups of objects (i.e. the cardinal aspect) as well as the numerical order.

In the object-file model there is no explicit, no direct representation of number (Feigenson, Carey, and Hauser 2002; Carey 2009; Piazza et al. 2011): the image of one object is first an object-image, the image of two objects is first the image of distinct, separated and individuated objects. The symbols $\square \square$, ... or $\square \square \square$ are primarily not symbols for numbers, not even for analogue magnitudes; they are symbols for individuals. They are in fact 'individual-files', this last expression being also more convenient in the case of events or sounds. As the title of an article by Feigenson and Halberda (2004) states, 'infants chunk objects arrays into sets of individuals'.

However, there is an implicit numerical content, that is to say a numerical content that is inferred from the direct representation, for there is one symbol for each individual. Feigenson (2005) showed that infants are sensitive to number in a simple habituation task, as long as the individuals in the set are not identical to each other; heterogeneity of properties draws attention to distinct individuals. By contrast homogeneous properties facilitate computations of cumulative continuous variables from representations of small sets of individuals: in some settings of Feigenson's cracker choice experiments, babies prefer a larger cracker over two smaller ones, each one-fourth the size of the larger one, but they are at chance if each of the smaller ones is one-half the size of the larger one. Thus, in certain cases, it seems that cumulative values of continuous variables 
(such as total surface area or total volume) are more salient than the number of objects in the set (Feigenson, Carey, and Hauser 2002; Feigenson, Carey, and Spelke 2002). This result contradicts the above-mentioned result stating that babies and animals prefer a bigger number of small chunks with a total quantity $X$ than a smaller number of bigger chunks with a total quantity $Y>X$. Cordes and Brannon $(2008,2009,2011)$ argue for a third interpretation: infants attend to both extent and number equally in the small numerosities $(<4)$ and prefer number over extent in case of large numerosities (> 3 items).

The bewildering variety of tested reactions shows how big the role of the experiment settings is and how difficult it is to draw definite conclusions from the testing outputs.

\subsection{Criticism of the Object-files Model}

Sets of mental file-objects are clearly thought by analogy with sets of marks such as $\bullet, \bullet \bullet$, •• or I, II, III, etc. Carey uses even the set-theoretical representation $\{i, j, k\}$, when the files are stored in long-term memory as prototypes for small quantities. The underlying model of object-files is clearly set-theoretical. ${ }^{17}$ Like the analogical number model, which is based on a visual conception of geometrical continuity, the object-file model also begs the question of the origin of our primary arithmetical representations and abilities by using the settheoretical framework, which is now commonly employed for axiomatizing abstract arithmetical concepts and constructions.

Marks such as I, II, III, etc. refer indeed to the numerical aspect as instantiated by sets of symbols such as $\square, \square \square, \square \square \square$, or •, ••, •••. But unlike object-files, such marks do not point to particular objects. There is a gap between the empirical root of object-indexes and the abstract meaning of-even small—cardinal numbers. Pylyshyn and Carey are bridging the gap by stressing, in different ways, the symbolic nature of the visual indexes/individual files for perceived objects.

Pylyshyn argues for a physically structured vision and for dissociation between visual and cognitive functions in the brain. He thinks that the visual system, as such, embodies natural constraints, what means that, insensitive to knowledge and processes of rational inference, vision is, nevertheless, solving visual problems mostly the way they need to be solved for the purposes of survival (Pylyshyn 1999, 2002). ${ }^{18}$

Carey thinks that concepts are, as mental symbols, 'encapsulated' in vision and that core cognition representations have a conceptual non-linguistic content (Carey 2009, 27, 67; 2011, 114). ${ }^{19}$ Also some form of conceptual activity is present in sensorial vision right from birth. Carey criticises Quine's linguistic determinism, arguing that core cognition is supporting language learning rather than resulting from it. In particular, she maintains that there is a 'set-based quantification system', which is 'part of the machinery children bring to the task of language learning, either as part of the language-acquisition device or as part of general representational capacities' (Carey 2009, 261). Relying on spatio-temporal information babies represent object as such long before they master the quantificational devices of natural language. Moreover, at about age of 12 months, then before language-acquisition, infants categorise objects on the basis of global kind, and kind representations are differentiated from representations of similarity based on perceptual properties. ${ }^{20}$ 


\subsection{Beyond Core Cognition: Natural Numbers}

How do we perform the inference from a perceived object to the thought of one object and from mental object-files representing real objects to the cardinal and the ordinal aspect of number?

There is patently a gap (a 'discontinuity' in Carey's language) between the resources of core cognition and the cultural construction of natural numbers. Can one bridge it? How? Carey thinks that it happens through bootstrapping (Neurath's and Quine's concept). Bootstrapping is a self-sustaining process that is supposed to allow the passage from empirical data to conceptual constructions without external input.

Carey thinks that bootstrapping is useless for constructing the concept of individual object from perceptual primitives, because this concept is part of the core cognition. But Carey (2009, ch. 8) proposes to flesh the bootstrapping metaphor by assuming that parallel individuation (which involves computations that embody the +1 operation), together with set-based quantification - the union of both two being then called 'enriched parallel individuation'- underlie the construction of the numeral list representation of number. According to such a solution of the gap, Gelman and Gallistel's counting principles (Gelman and Gallistel 1978) do not result from core cognition alone but from a conceptual construction anchored in core cognition (Lecorre and Carey 2005, 2008). However, there is no consensus on Carey's interpretations. ${ }^{21}$

\subsection{Perceiving an Object qua Object and Perceiving One Object as One Object}

(1) It is not really clear that a core cognition system of representation of objects has implicit representations of numbers. Experts of the structure of the visual sense as an information processor (e.g. Pylyshyn) maintain that perceiving entities as objects requires only coordination between perceptual memory and perceptual anticipation. Speaking of the structure of vision does not mean that an early form of conceptualisation is embedded in that structure. Pylyshyn endorses David Marr's theory of 'early vision', according to which there is dissociation between visual and cognitive functions in the brain. According to Pylyshyn the visual index is certainly a symbol but certainly not a concept. We may have iconic representations of objects but no iconic representation of object is the concept of object (see also Gauker 2011). Pylyshyn writes:

We pick out and individuate primitive visual objects as a precursor to focusing attention on them and encoding their properties. Such visual indexes play an important role in attaching symbols to things and they also play a role in allowing visual images to inherit spatial properties of perceived space. (Pylyshyn 2002, vii; emphasis added)

Also spatio-temporal parameters and numerical categorisation do not come into play in vision of objects qua objects, what means that perceiving an object qua object is not perceiving an object as physical object and that perceiving one object qua object precedes the perception of one object as one object.

(2) Tyler Burge criticises harshly Carey's view on the basis of his own theory of perception, which combats all intellectualist interpretations. He argues: 


\begin{abstract}
It is a mistake to require of a system that has object representations that it have quantificational devices, or representations of criteria for numerical identity, or specifications of continuity under loss of perceptual contact (using that 'vocabulary'). Nor need object perception represent particulars as persisting, or as independent of an observer, or as unperceived, in order to perceptually represent something as an object or body. A perception of objects need not represent persistence, observers, perceptual contact, or independence from observers. Such requirements confuse principles according to which perception operates with representations that occur in perceptual object representation.... Perceptual representations include object (body) perceptions. There is substantial evidence that perceptual body representations occur in the visual systems of many mammals and some birds. Anticipations of continuities that are relevant to perceiving entities as bodies are associated with very early vision. The anticipations are not matters of conception or prediction. (Burge 2011; emphasis in original)
\end{abstract}

For scientists like Marr, Pylyshyn, and Burge the physiological structure of vision provides the perception of particular objects qua objects, without any kind of specification (numerical, geometrical, temporal, etc.).

Then, I would say that as for the origins of the concept of number we are happy neither with the MNL nor with a set-theoretical mental image of objects and neither with a protophysics of spatio-temporal bodies of the real world nor with their associated mental iconic representation as object-files, and naturally not with the alone resources of natural languages. Describing empirical data (given by fMRI or EEG or sets of responses in the frame of experimental settings) through scientific models tells something about how we understand the empirical data rather than about the crude data themselves or about the grounding role of the abstract models. Models are models, that is, fruitful tools for exploring and understanding reality; they are neither the reality itself nor its duplicate.

\title{
6. Conclusions
}

I hope that I have shed some light on the following points.

(1) The experiments about mathematical cognition involve theoretical preconceptions of the nature of mathematical objects and of the basis of our arithmetical abilities. In particular there is a petitio principii, it seems to me, in interpreting data of testing how animals, infants or adults understand and carry out very elementary arithmetical operations in terms of modern and sophisticated mathematical models. Geometric, set-theoretical, metaphorical, computational, connectionist, etc. models are valuable means of understanding. They need not be thought as means of disclosing the foundations of arithmetic.

(2) Scientists want to replace philosophical questioning by scientific methods of investigation. In the same time they cannot but refer to philosophical concepts and paradigms. They include fragments of established philosophical theories (most times Kant, Quine, Fodor) in the framing of empirical data and that goes often along with an unwitting distortion of those theories in order to make them suitable for the intended interpretations of the empirical experiments. For instance, in the project of a 'Kantian research programme' on space, time and number proposed by Dehaene and Brannon (2010), one can fear a misuse of Kant's transcendental 
schematism. Indeed, in Kant's theory of knowledge the scheme is neither an image nor a representation, it is the rule or the a priori condition that makes possible the representation. It is also the link between categories (i.e. pure concepts of the understanding) and the phenomenal appearance of objects in general. The mental representation, which has a temporary pictorial or symbolic content, is to be carefully distinguished from the Kantian formal, fix and universal rule that produces images. Let me quote Kant's own explanations:

The schema is to be distinguished from an image. Thus, if I place five points in a row, ....., this is an image of the number five. On the contrary, if I only think a number in general, which could be five or a hundred, this thinking is more the representation of a method for representing a multitude (e.g. a thousand) in accordance with a certain concept than the image itself, which in this case I could survey and compare with the concept only with difficulty. Now this representation of a general procedure of the imagination for providing a concept with its image is what I call the schema for this concept. (Kant [1781-1787] 1956, A140-141/B179-180; emphasis added)

What can remain from Kant's conception of the a priori pure intuitions when the main goal is to address questions 'empirically, with a combination of behavioural, neuroimaging and neurophysiological methods in animals, preverbal infants, children and adults' (Dehaene and Brannon 2010, 518)? And thinking that 'nature founded the bases of arithmetic on the most fundamental laws of physics' (Dehaene 2011, 48) or that 'in the course of their evolution, humans and many other animal species might have internalized basic codes and operations that are isomorphic to the physical and arithmetic laws that govern the interaction of objects in the external world' (Dehaene and Brannon 2010, 517; emphasis added) is it not the exact opposite of Kant's central view of the transcendental apperception? Indeed, in Kant's view pure concepts of the understanding are subjective and a priori conditions of perceiving the external diversity as a lawful world of phenomena, and 'nature direct[s] itself according to our subjective ground of apperception, indeed in regard to its lawfulness even depend[s] on this' (Kant [1781-1787] 1956, A114).

It is not prohibited to try to naturalise Kant's subjectivist conception by reducing the transcendental to an empirical level, but one should be aware of the reduction and of its consequences.

(3) Most cognitive scientists, if not all, believe that they can really give the or a firm ground to the objective arithmetical processes and to our arithmetical abilities and acts. However in empirical sciences, such as physics, biology, psychology, neurosciences, sociology, etc., the right aim is at grasping and describing dynamical processes and at establishing correlations between different types of data, without necessary appeal to causes or to grounds, let alone to a single ground. The philosophical idea of foundation was flourishing in the twentieth century. Mathematicians with different leanings (Frege, Russell, Dedekind, Hilbert, Brouwer, Poincaré, Weyl) strove to bring to light the essence or the foundation of numbers. But the foundational aim does not match well with the spirit and methods of empirical sciences. In contemporary philosophy itself the idea of foundation is not always welcome. Notably Wittgenstein argues for the irrelevance of the foundational outlook in his Remarks on the Foundations of Mathematics. He promotes instead semantic analysis and language 
games. More generally, one may consider that the force of a science lies much more in its internal dynamism than in its foundational claims about knowledge.

(4) It seems hard to draw a global and coherent philosophical view from the huge number of the fragmented, variable, and sometimes uneasily compatible or fully divergent results obtained by experimentation. For instance, Wynn's addition and subtraction experiment (Wynn 1992) is not always replicable (see Wakeley, Rivera, and Langer 2000). Experimental findings depend on the hypotheses one puts to the test, on the designs and material conditions of the test, on the complexity of stimuli, on the age, cultural and socioeconomic condition of the observed subject, on the models used to organise and represent a set of data, and on the explicit or tacit philosophical assumptions one has in mind. Moreover, one and the same experimental result may be interpreted in different ways. The theoretic meaning of experimental results is not something intrinsically obvious.

It is fair to say that many scientists do not deny the speculative character of their hypotheses and interpretations, e.g. Spelke:

Like any other branch of science, the study of cognitive development is not an exercise in logic resulting in irrefutable conclusion. Hypotheses can be rejected or supported by evidence but can never be proven correct. Because there are an infinite number of alternative interpretations of any finding in any area of science, empirical progress requires that scientists select and evaluate interpretations in accord with evidence, not in accord with a priori preferences for some interpretations over others. (Spelke 1998, 190-191)

Yet I think it is hard to totally avoid a priori preferences or bias and to describe empirical observations free from imposed theoretical interpretations. Most time, justifications are partial and they are never totally indisputable. In spite of that, cognitive scientists do not hesitate to extrapolate from partial experimental data general interpretations involving philosophical previews about the presumed roots or grounds of primary arithmetical activity. I can understand the need to unify various data in a general framework. But I deem it would be wise to question the idea of ground and to make a distinction between scientific explanations, be they the prior result of experiments or of some mathematical expression and treatment of experiments, on the one hand, and ground on the other hand. An explanation is not exclusive and it is revisable, while grounding corresponds to the ambition to give an ultimate explanation. An explanation connects $B$ to $A$ through a causal mechanism or simply through a correlation, while grounding involves or suggests a constitutive form of determination of $B$ by $A$, and, consequently, opens the door for a more or less strong determinism. Substantiating this and some other differences between explanation and grounding is worth further work. ${ }^{22}$

\section{Notes}

1. 'Cognitive' means pertaining to the action or process of knowing and is used for 'any kind of mental operation or structure that can be studied in precise terms' (Lakoff and Johnson 1999, 11). So it should not be confused with the narrow concept used in some traditions of analytic philosophy, where 'cognitive' refers only to formal rules and truth conditional semantics.

2. Nativism is sometimes contested, for instance in Stewart (1993), Elman et al. (1996), Palmer (2000), and Lécuyer and Durand (2012).

3. In particular, contrary to Piaget's theory, 'out of sight' is not 'out of mind'. 
4. Renée Baillargeon and Elizabeth Spelke introduced the 'violation-of-expectation lookingtime methodology' in the mid-1980s. Samples of experiments using this methodology are given in Carey $(2009,40-48)$.

5. It has been alternatively suggested that the approximate number system supports also the understanding of ordinal relation (for instance McCrink and Birdsall 2015, 263).

6. Alternatively, Barsalou $(1999,2008)$ and Campbell $(2015)$ argue that elementary arithmetic is not based on amodal representations and they emphasize embodied cognitive processes.

7. Dehaene $(2011,49)$ mentions another experiment: watching a picture with two forks, one fork broken into two pieces, a 3- or 4-year-old child counts the broken fork twice and says that the total number of forks equals three.

8. For a discussion of technical aspects see Harvey et al. (2013) and Campbell (2015).

9. However some experiments show that the SNARC is linked with the ordinal position in a sequence rather than with the cardinal aspect of things. An alternative to Dehaene's interpretation is given in van Dijck et al. (2015).

10. Brian C. Goodwin defended a non-reductionist structural view and criticized the excesses of Neo-Darwinism: see in particular Goodwin $(1993,1994)$.

11. Spelke (1983, 1985, 1990, 1993): 'Infants divide perceptual arrays into units that move as connected wholes, that move separately from one another, that tend to maintain their size and shape over motion, and that tend to act upon each other only on contact.'

12. Dehaene adopted the two-systems view: Feigenson, Dehaene, and Spelke (2004), Revkin et al. (2008).

13. The model of object-files was proposed in Treisman, Kahneman, and Burkell (1983), Kahnemann, Treisman, and Gibbs (1992), Pylyshyn and Storm (1998), and Pylyshyn (2003a).

14. This distinction appeared first in Pylyshyn (2003b).

15. 'Focal attention is typically directed to objects rather than to places and therefore the earliest stages of vision are concerned with individuating objects and that when visual properties are encoded they are encoded as properties of individual objects' (Pylyshyn 2003a, 4, 13; emphasis in the original).

16. By contrast, according to Pylyshyn object tracking is engraved in the visual architecture; therefore the spatio-temporal parameters of the object do not come into play.

17. It has been argued that set representations are required for acquisition of the number concept: Halberda and Feigenson (2008). Thus the set-theoretical model is supposed to mirror the real development of children; though this model was invented in the nineteenth century by Bernard Bolzano, Richard Dedekind, and Georg Cantor, it was taught very recently. As Hodes (2008) notes, cognitive scientists are 'overly quick to ascribe the possession of certain concepts to children (and of set-theoretic concepts to non-mathematicians)'.

18. See also Burge (2011), 125: 'There is substantial evidence that perceptual body representations occur in the visual systems of many mammals and some birds. Anticipations of continuities that are relevant to perceiving entities as bodies are associated with very early vision. The anticipations are not matters of conception or prediction'.

19. See also Barsalou $(1999,2008)$ for support of the view that categorization is grounded in the sensorimotor regions of the brain, and Lakoff and Johnson (1999) for an argument that abstract concepts are grounded metaphorically in embodied and situated knowledge.

20. For alternative views see e.g. Weiskopf (2008): percept and concept are not ontologically but functionally distinct, and Weiskopf (2009): concepts are not a single, uniform kind of psychological entity, but are constituted by multiple representational kinds, with the particular kind of concept used on an occasion being determined by properties of the context.

21. According to Barsalou's 'grounded cognition', cognition does not reside in a separate semantic memory system; it shares mechanisms with the brain's modal systems for perception, action and introspection (Barsalou 2008). By contrast, Núñez argues that numbers are not hard-wired. According to him, the leap to number concepts proper relies, in part, on two embodied, domain-general cognitive mechanisms: conceptual metaphor and fictive motion. Conceptual metaphor is both a particular inference-preserving cross-domain mapping, and the cognitive mechanism that enables such mapping. Fictive motion is a 
cognitive mechanism through which we unconsciously and effortlessly conceptualize static entities in dynamic terms (Lakoff and Núñez 2000; Núñez 2009; Núñez and Marghetis 2015). See also Harnad (1987), Neisser (1987), Medin (1989); Rips, Bloomfield, and Asmuth (2008).

22. Actually, a big amount of logical and metaphysical contemporary reflections is devoted to examining the relations between explanation and grounding. See for instance Correia and Schnieder (2012). Taking into account such current research would help to make philosophical interpretations of scientific experiments more cautious.

\section{Acknowledgements}

Since my article, 'Philosophie de la neuropsychologie du nombre', published in 2014 in Intellectica and for which I benefited from the remarks of John Stewart, I have had the opportunity to expound roughly the same content in the workshop, 'Philosophy of Mathematics and Logic', organised by José Ferreirós at the Universidad de Sevilla, the proceedings of which were published in 2016. Different versions constituted the content of a talk in the ANR-DFG workshop, 'Mathematics: Objectivity by Representation', organised by Hanns Leitgeb and Gerhard Heinzmann at the Ludwig-Maximilians-Universität München (November 2014), and of another talk in the Colloquium de Mathématiques directed by Henri Lombardi at the Université de Franche-Comté, Besançon (March 2015). I still talked about the same subject at the thematic trimester 'Current Issues in the Philosophy of Practice of Mathematics and Informatics' organised by Sébastien Maronne at the Mathematical Institute of the Université de Toulouse. Questions and comments from the audience in general and from Jeremy Avigad and Paolo Mancosu in particular led me to deepen my philosophical analysis and to present a completely new version at the 43rd Annual Philosophy of Science Conference, Inter-University Centre, Dubrovnik, April 2016. I thank Michel Ghins for inviting me to this conference, the participants for their useful comments, and James W. McAllister for inviting me to turn the talk into a paper for International Studies in the Philosophy of Science.

\section{References}

Anderson, M. L. 2010. "Neural Reuse: A Fundamental Organizational Principle of the Brain." Behavioral and Brain Sciences 33: 245-266.

Anderson, M. L., and M. Penner-Wilger. 2013. "Neural Reuse in the Evolution and Development of the Brain." Developmental Psychobiology 55: 42-51.

Barsalou, L. W. 1999. "Perceptions of Perceptual Symbols." Behavioral and Brain Sciences 22: 637660.

Barsalou, L. W. 2008. “Grounded Cognition.” Annual Review of Psychology 59: 617-645.

Benis Sinaceur, H. 2014a. "Facets and Levels of Mathematical Abstraction.” Philosophia Scientiae 18 (1): 81-112.

Benis Sinaceur, H. 2014b. "Philosophie de la neuropsychologie du nombre." Intellectica 62: 103144.

Benis Sinaceur, H. 2016. "Filosofía de la biopsicologia del número." In El árbol de los números. Cognición, lógica y prática matematica, edited by J. Ferreirós Domínguez and A. Lassalle Casanave, 77-118. Sevilla: Editorial Universidad de Sevilla.

Brannon, E. M. 2002. "The Development of Ordinal Numerical Knowledge in Infancy." Cognition 83: 223-240.

Burge, T. 2011. "Border Crossings: Perceptual and Post-perceptual Object Representation." Behavioral and Brain Sciences 34: 125.

Butterworth, B. 1999. The Mathematical Brain. London: Macmillan.

Campbell, J. I. D. 2015. "How Abstract Is Arithmetic?" In The Oxford Handbook of Numerical Cognition, edited by R. Cohen Kadosh and A. Dowker, 140-157. Oxford: Oxford University Press.

Carey, S. 2009. The Origin of Concepts. New York: Oxford University Press. 
Carey, S. 2011. "Précis of The Origin of Concepts." Behavioral and Brain Sciences 34: 113-124.

Carey, S., and F. Xu. 2001. "Beyond Object-files and Object Tracking: Infants' Representations of Objects." Cognition 80: 179-213.

Chinello, A., V. Cattani, C. Bonfiglioli, S. Dehaene, and M. Piazza. 2013. "Objects, Numbers, Fingers, Space: Clustering of Ventral and Dorsal Functions in Young Children and Adults." Developmental Science 16: 377-393.

Church, R. M., and W. H. Meck. 1984. “The Numerical Attribute of Stimuli.” In Animal Cognition, edited by H. L. Roitblat, T. G. Bever, and H. S. Terrace, 445-464. Hillsdale, NJ: Erlbaum.

Cordes, S., and E. M. Brannon. 2008. "The Difficulties of Representing Continuous Extent in Infancy: Using Number Is Just Easier.” Child Development 79: 476-489.

Cordes, S., and E. M. Brannon. 2009. "Crossing the Divide: Infants Discriminate Small from Large Numerosities.” Developmental Psychology 45: 1583-1594.

Cordes, S., and E. M. Brannon. 2011. "Attending to One of Many: When Infants Are Surprisingly Poor at Discriminating an Item's Size." Frontiers in Psychology 2: 65.

Correia, F., and B. Schnieder, eds. 2012. Metaphysical Grounding: Understanding the Structure of Reality. Cambridge: Cambridge University Press.

Coubart, A., V. Izard, E. S. Spelke, J. Marie, and A. Streri. 2014. "Dissociation Between Small and Large Numerosities in Newborn Infants." Developmental Science 17: 11-22.

Dantzig, T. 1954. Number: The Language of Science. 2nd ed. New York: Free Press.

Dehaene, S. 2001. "Précis of The Number Sense." Mind and Language 16: 16-36.

Dehaene, S. 2011. The Number Sense: How the Mind Creates Mathematics. Revised ed. New York: Oxford University Press.

Dehaene, S., S. Bossini, and P. Giraux. 1993. "The Mental Representation of Parity and Numerical Magnitude.” Journal of Experimental Psychology: General 122: 371-396.

Dehaene, S., and E. M. Brannon. 2010. "Space, Time, and Number: A Kantian Research Program.” Trends in Cognitive Sciences 14: 517-519.

Dehaene, S., and J. P. Changeux. 1993. "Development of Elementary Numerical Abilities: A Neuronal Model." Journal of Cognitive Neuroscience 5: 390-407.

Dehaene, S., and L. Cohen. 1991. "Two Mental Calculation Systems: A Case Study of Severe Acalculia with Preserved Approximation.” Neuropsychologia 29: 1045-1074.

Dehaene, S., and L. Cohen. 1997. "Cerebral Pathways for Calculation: Double Dissociation Between Rote Verbal and Quantitative Knowledge of Arithmetic." Cortex 33: 219-250.

De Hevia, M. D., and E. S. Spelke. 2010. "Number-space Mapping in Human Infants." Psychological Science 21: 653-660.

Elman, J. L., E. A. Bates, A. Karmiloff-Smith, M. H. Johnson, D. Parisi, and K. Plunkett. 1996. Rethinking Innateness: Connectionism in a Developmental Framework. Cambridge, MA: MIT Press.

Feigenson, L. 2005. “A Double-dissociation in Infants' Representations of Object Arrays.” Cognition 95: B37-B48.

Feigenson, L., and S. Carey. 2003. “Tracking Individuals via Object-files: Evidence from Infants' Manual Search.” Developmental Science 6: 568-584.

Feigenson, L., S. Carey, and M. Hauser. 2002. “The Representations Underlying Infants' Choice of More: Object Files Versus Analog Magnitudes.” Psychological Science 13: 150-156.

Feigenson, L., S. Carey, and E. S. Spelke. 2002. "Infants' Discrimination of Number vs. Continuous Extent." Cognitive Psychology 44: 33-66.

Feigenson, L., S. Dehaene, and E. S. Spelke. 2004. "Core Systems of Number." Trends in Cognitive Sciences 8: 307-314.

Feigenson, L., and J. Halberda. 2004. "Infants Chunk Object Arrays into Sets of Individuals." Cognition 91: 173-190.

Feigenson, L., and E. S. Spelke. 1998. "Numerical Knowledge in Infancy: The Number/Mass Distinction." Poster, International Conference on Infant Studies, Atlanta, GA.

Fodor, J. A. 1975. The Language of Thought. Cambridge, MA: Harvard University Press.

Fodor, J. A., and Z. W. Pylyshyn. 1988. "Connectionism and Cognitive Architecture: A Critical Analysis." Cognition 28: 3-71. 
Frege, G. [1884] 1953. The Foundations of Arithmetic: A Logico-mathematical Enquiry into the Concept of Number. Translated by J. L. Austin. New York: Harper.

Gallistel, C. R., and R. Gelman. 1978. The Child's Understanding of Number. Cambridge, MA: Harvard University Press.

Gallistel, C. R., and R. Gelman. 2000. "Non-verbal Numerical Cognition: From Reals to Integers." Trends in Cognitive Sciences 4: 59-65.

Gallistel, C. R., and R. Gelman. 2005. "Mathematical Cognition.” In The Cambridge Handbook of Thinking and Reasoning, edited by K. Holyoak and R. Morrison, 559-588. Cambridge: Cambridge University Press.

Gauker, C. 2011. "Concepts Are Not Icons." Behavioral and Brain Sciences 34: 127.

Gelman, S. A. 2003. The Essential Child: Origins of Essentialism in Everyday Thought. New York: Oxford University Press.

Gelman, S. A. 2004. "Psychological Essentialism in Children." Trends in Cognitive Sciences 8: 404409.

Gelman, R., and C. R. Gallistel. 1978. The Child's Understanding of Number. Cambridge, MA: Harvard University Press.

Gelman, S. A., and H. Wellman. 1991. "Insides and Essences: Early Understandings of the Nonobvious." Cognition 38: 213-244.

Giaquinto, M. 2015. "Philosophy of Number." In The Oxford Handbook of Numerical Cognition, edited by R. Cohen Kadosh and A. Dowker, 17-31. Oxford: Oxford University Press.

Goodwin, B. C. 1993. "La genèse de formes dynamiques. L'organisme et l'esprit." Intellectica 16: $45-60$.

Goodwin, B. C. 1994. How the Leopard Changed Its Spots: The Evolution of Complexity. New York: Scribner.

Gopnik, A. 2003. “The Theory Theory as an Alternative to the Innateness Hypothesis.” In Chomsky and His Critics, edited by L. M. Antony and N. Hornstein, 238-254. New York: Basil Blackwell.

Halberda, J., and L. Feigenson. 2008. "Set Representations Required for the Acquisition of the 'Natural Number' Concept." Behavioral and Brain Sciences 31: 655-656.

Harnad, S. 1987. "Psychophysical and Cognitive Aspects of Categorical Perception: A Critical Overview." In Categorical Perception: The Groundwork of Cognition, edited by S. Harnad, 125. Cambridge: Cambridge University Press.

Harvey, B. M., B. P. Klein, N. Petridou, and S. O. Dumoulin. 2013. “Topographic Representation of Numerosity in the Human Parietal Cortex." Science 341: 1123-1126.

Hilbert, D. 1918. “Axiomatisches Denken.” Mathematische Annalen 78: 405-415.

Hodes, H. 2008. "On Some Concepts Associated with Finite Cardinal Numbers." Behavioral and Brain Sciences 31: 657-658.

Hubbard, E. M., M. Piazza, P. Pinel, and S. Dehaene. 2005. "Interactions Between Number and Space in Parietal Cortex." Nature Reviews Neuroscience 6: 435-448.

Hyde, D., and E. S. Spelke. 2009. "All Numbers Are Not Equal: An Electrophysiological Investigation of Small and Large Number Representations." Journal of Cognitive Neuroscience 21: 1039-1053.

Hyde, D., and E. S. Spelke. 2011. "Neural Signatures of Number Processing in Human Infants: Evidence for Two Core Systems Underlying Numerical Cognition.” Developmental Science 14: $360-371$.

Izard, V., G. Dehaene-Lambertz, and S. Dehaene. 2008. "Distinct Cerebral Pathways for Object Identity and Number in Human Infants." PLoS Biology 6 (2): e11.

Izard, V., P. Pica, E. S. Spelke, and S. Dehaene. 2008. "Exact Equality and Successor Function: Two Key Concepts on the Path Towards Understanding Exact Numbers.” Philosophical Psychology 21: 491-505.

Izard, V., C. Sann, E. S. Spelke, and A. Streri. 2009. "Newborn Infants Perceive Abstract Numbers.” Proceedings of the National Academy of Sciences of the USA 106: 10382-10385.

Kahnemann, D., A. Treisman, and B. J. Gibbs. 1992. "The Reviewing of Object Files: Object-specific Integration of Information." Cognitive Psychology 24: 175-219.

Kant, I. [1781-1787] 1956. Kritik der reinen Vernunft. Hamburg: Felix Meiner. 
Lakoff, G., and M. Johnson. 1999. Philosophy in the Flesh: The Embodied Mind and Its Challenge to Western Thought. New York: Basic Books.

Lakoff, G., and R. Núñez. 2000. Where Mathematics Comes from: How the Embodied Mind Brings Mathematics into Being. New York: Basic Books.

Lecorre, M., and S. Carey. 2005. "One, Two, Three, Four, Nothing More: An Investigation of the Conceptual Sources of the Verbal Counting Principles." Cognition 105: 395-438.

Lecorre, M., and S. Carey. 2008. "Why the Verbal Counting Principles Are Constructed out of Representations of Small Sets of Individuals: A Reply to Gallistel." Cognition 107: 650-662.

Lécuyer, R. 2002. “Introduction: Inné fable?" Intellectica 34: 11-28.

Lécuyer, R., and K. Durand. 2012. “Aux sources de la connaissance. L'état du débat constructivisme/ nativisme chez le très jeune enfant." Devenir 24: 181-214.

Lourenco, S., and M. R. Longo. 2010. "General Magnitude Representation in Human Infants." Psychological Science 21: 873-881.

McCrink, K., and W. Birdsall. 2015. "Numerical Abilities and Arithmetic in Infancy." In The Oxford Handbook of Numerical Cognition, edited by R. Cohen Kadosh and A. Dowker, 258-274. Oxford: Oxford University Press.

Medin, D. L. 1989. “Concepts and Conceptual Structure.” American Psychologist 44: 1469-1481.

Neisser, U. 1987. Concepts and Conceptual Development: Ecological and Intellectual Factors in Categorization. Cambridge: Cambridge University Press.

Nieder, A. 2005. "Counting on Neurons: The Neurobiology of Numerical Competence." Nature Reviews Neuroscience 6: 177-190.

Nieder, A., and E. K. Miller. 2003. “Coding of Cognitive Magnitude.” Neuron 37: 149-157.

Nieder, A., and E. K. Miller. 2004. "A Parieto-frontal Network for Visual Numerical Information in the Monkey." Proceedings of the National Academy of Sciences of the USA 101: 7457-7462.

Núñez, R. 2009. "Numbers and Arithmetic: Neither Hard-wired nor Out There." Biological Theory 4: $68-83$.

Núñez, R. 2011. "No Innate Number Line in the Human Brain." Journal of Cross-cultural Psychology 42: 651-668.

Núñez, R., and T. Marghetis. 2015. "Cognitive Linguistics and the Concept(s) of Number." In The Oxford Handbook of Numerical Cognition, edited by R. Cohen Kadosh and A. Dowker, 377-401. Oxford: Oxford University Press.

Palmer, D. C. 2000. "Chomsky's Nativism: A Critical Review." Analysis of Verbal Behavior 17: 39-50.

Palmer, D. C. 2002. "Psychological Essentialism: A Review of E. Margolis and S. Laurence (eds.), Concepts: Core Readings." Journal of the Experimental Analysis of Behavior 78: 597-607.

Palmer, D. C., and J. W. Donahoe. 1992. "Essentialism and Selectionism in Cognitive Science and Behavior Analysis.” American Psychologist 47: 1344-1358.

Piaget, J. [1953] 1973. Introduction à l'épistémologie génétique. Vol. 1, La pensée mathématique. 2nd ed. Paris: Presses Universitaires de France.

Piazza, M., A. Fumarola, A. Chinello, and D. Melcher. 2011. "Subitizing Reflects Visuo-spatial Object Individuation Capacity." Cognition 121: 147-153.

Platt, J., and D. M. Johnson. 1971. "Localization of Position within a Homogeneous Behavior Chain: Effects of Error Contingencies." Learning and Motivation 2: 386-414.

Pylyshyn, Z. W. 1999. "Is Vision Continuous with Cognition? The Case for Cognitive Impenetrability of Visual Perception." Behavioral and Brain Sciences 22: 341-423.

Pylyshyn, Z. 2002. "Mental Imagery: In Search of a Theory." Behavioral and Brain Sciences 25: 157-182.

Pylyshyn, Z. W. 2003a. Seeing and Visualizing: It's Not What You Think. Cambridge, MA: MIT Press.

Pylyshyn, Z. W. 2003b. "Return of the Mental Image: Are There Really Pictures in the Brain?" Trends in Cognitive Sciences 7: 113-118.

Pylyshyn, Z. W., and R. W. Storm. 1998. "Tracking Multiple Independent Targets: Evidence for a Parallel Tracking Mechanism.” Spatial Vision 3: 179-197. 
Revkin, S., M. Piazza, V. Izard, L. Cohen, and S. Dehaene. 2008. “Does Subitizing Reflect Numerical Estimation?” Psychological Science 19: 607-614.

Rips, L. J., A. Bloomfield, and J. Asmuth. 2008. "From Numerical Concepts to Concepts of Number." Behavioral and Brain Sciences 31: 623-642.

Roitman, J. D., E. M. Brannon, and M. L. Platt. 2007. "Monotonic Coding of Numerosity in Macaque Lateral Intraparietal Area.” PLoS Biology 5 (8): e208.

Roitman, J. D., E. M. Brannon, and M. L. Platt. 2012. "Representation of Numerosity in Posterior Parietal Cortex." Frontiers in Integrative Neuroscience 6, article 25.

Silver, R. A. 2010. "Neuronal Arithmetic." Nature Reviews Neuroscience 11: 474-489.

Simon, O., J. F. Mangin, L. Cohen, D. Le Bihan, and S. Dehaene. 2002. "Topographical Layout of Hand, Eye, Calculation, and Language-related Areas in the Human Parietal Lobe." Neuron 33: 475-487.

Spelke, E. S. 1983. “Cognition in Infancy.” MIT Occasional Papers in Cognitive Science, no. 23.

Spelke, E. S. 1985. "Perception of Unity, Persistence, and Identity: Thoughts on Infants' Conceptions of Objects." In Neonate Cognition: Beyond the Blooming, Buzzing Confusion, edited by J. Mehler and R. Fox, 89-113. Hillsdale, NJ: Erlbaum.

Spelke, E. S. 1990. "Principles of Object Perception." Cognitive Science 14: 29-56.

Spelke, E. S. 1993. "Gestalt Relations and Object Perception: A Developmental Study." Perception 22: 1483-1501.

Spelke, E. S. 1998. "Nativism, Empiricism, and the Origins of Knowledge." Infant Behavior and Development 21: 181-200.

Spelke, E. S., V. Izard, A. Coubart, M. D. de Hevia, and A. Streri. 2014. "Representations of Space, Time, and Number in Neonates." Proceedings of the National Academy of Sciences of the USA 111: 4808-4813.

Starkey, P., E. S. Spelke, and R. Gelman. 1983. "Detection of Intermodal Numerical Correspondences by Human Infants." Science 222: 179-181.

Starkey, P., E. S. Spelke, and R. Gelman. 1990. "Numerical Abstraction by Human Infants." Cognition 36: 97-127.

Starr, A., M. Libertus, and E. M. Brannon. 2013. "Infants Show Ratio-dependent Number Discrimination Regardless of Set Size." Infancy 18: 927-941.

Stewart, J. 1993. “Au-delà de l'inné et de l'acquis.” Intellectica 16: 151-174.

Treisman, A. M., D. Kahneman, and J. Burkell. 1983. "Perceptual Objects and the Cost of Filtering." Perception and Psychophysics 33: 527-532.

van Dijck, J.-P., V. Ginsburg, L. Girelli, and W. Gevers. 2015. "Linking Numbers to Space: From the Mental Number Line Towards a Hybrid Account." In The Oxford Handbook of Numerical Cognition, edited by R. Cohen Kadosh and A. Dowker, 89-105. Oxford: Oxford University Press.

Wakeley, A., S. Rivera, and J. Langer. 2000. "Can Young Infants Add and Subtract?" Child Development 71: 1525-1534.

Walsh, V. 2003. "A Theory of Magnitude: Common Cortical Metrics of Time, Space and Quantity.” Trends in Cognitive Sciences 7: 483-488.

Weiskopf, D. 2008. "First Thoughts." Philosophical Psychology 21: 251-268.

Weiskopf, D. 2009. "The Plurality of Concepts." Synthese 169: 145-173.

Wynn, K. 1992. “Addition and Subtraction by Human Infants.” Nature 358: 749-750.

Wynn, K. 1996. "Infants' Individuation and Enumeration of Actions." Psychological Science 7: 164-169.

Wynn, K. 1998. "Psychological Foundations of Number: Numerical Competence in Human Infants." Trends in Cognitive Sciences 2: 296-303.

Xu, F. 2003. "Numerosity Discrimination in Infants: Evidence for Two Systems of Representations." Cognition 89: B15-B25.

Xu, F., and S. Carey. 1996. "Infants' Metaphysics: The Case of Numerical Identity." Cognitive Psychology 30: 111-153.

Xu, F., S. Carey, and J. Welsh. 1999. "Infants' Ability to Use Object Kind Information for Object Individuation." Cognition 70: 137-166.

Xu, F., and E. S. Spelke. 2000. "Large Number Discrimination in 6-month-old Infants." Cognition 74: B1-B11. 